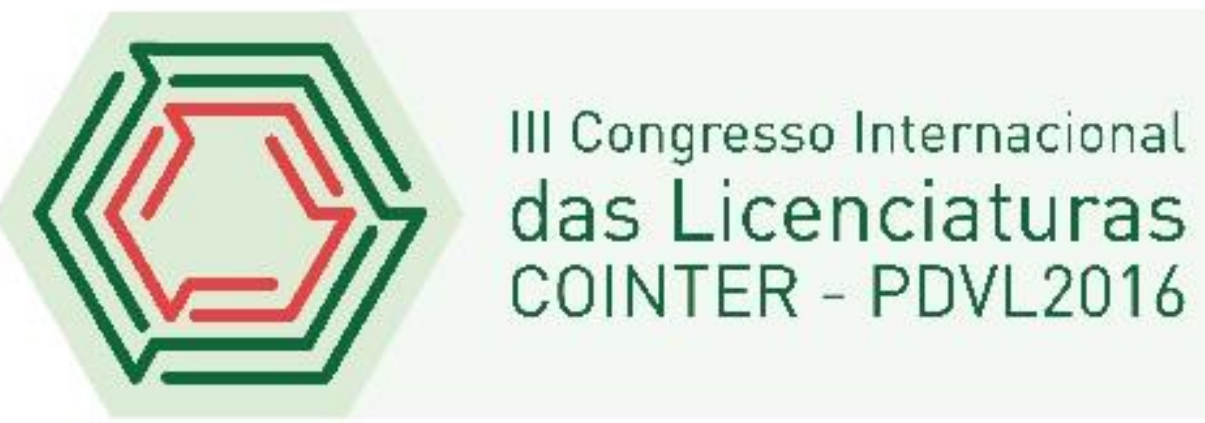

\title{
UNOOXIGENADO UM JOGO DIDÁTICO NO ENSINO DE QUÍMICA
}

\author{
Apresentação: Pôster
}

\begin{abstract}
Ayrton Matheus da Silva Nascimento ${ }^{1}$; Kilma da Silva Lima Viana ${ }^{2}$
\end{abstract}
\section{Introdução}

O uso de jogos e atividades lúdicas com finalidades educativas tem sido observado em diversas culturas ao longo da história da humanidade. Mesmo povos considerados guerreiros e com formação humana voltada para as práticas bélicas, como os espartanos no século IX a.C., consideravam uma educação lúdica importante até por volta dos doze anos de idade, em que os jovens desenvolviam o estudo de música, canto e danças coletivas (ARANHA, 1996).

Para Soares (2008), a atividade lúdica pode ainda ser definida como uma ação divertida, relacionada aos jogos, seja qual for o contexto linguístico, com ou 24 sem a presença de regras, sem considerar o objeto envolto nesta ação. É somente uma ação que gera um mínimo de divertimento. Entendemos que este seja realmente um dos principais motivos de aplicações de atividades lúdicas darem tão certo no ensino. Hoje se discute uma maneira de deixar o ensino mais atrativo para o aluno evitando abandono, desistências no meio do semestre, evasão e repetências. (EVANGELISTA, 2009).

Neste contexto, elaboração um jogo didático, que servirá como proposta para ser utilizado em sala de aula na disciplina de Química no conteúdo de Funções Oxigenadas como um instrumento inédito. Considerando as características lúdicas relacionadas com a aprendizagem, que denominamos UnoOxigenados, um jogo que aborda de forma diferenciada o conteúdo químico relacionado as "Funções Oxigenadas".

\section{Fundamentação Teórica}

Os jogos são necessariamente uma atividade lúdica, mas, nem toda atividade lúdica é um jogo, segundo algumas definições de uso rotineiro no Brasil e em alguns dicionários. Em termos de

\footnotetext{
${ }^{1}$ Aluno de Pós - Graduação em Ciências de Materiais, UFPE - campus Recife, ayrthon.matheus@gmail.com

${ }^{2}$ Doutora em Ensino de Ciências, UFPE - campus Recife, kilma.viana@vitoria.ifpe.edu.br
} 
definição, os jogos, as atividades lúdicas e jogo educativo 22 respondem a significados muito próximos, não iguais, mas complementares. Brougère (1998), sobre a polissemia e o uso do vocábulo jogo, nos esclarece:

Definir jogo requer antes de tudo entender o que significa o vocábulo jogo. A que corresponde tal palavra, quais são seus usos legítimos? Podemos dar a ele uma definição, uma delimitação? O jogo é polissêmico e ambíguo como o uso da palavra jogo para diferentes situações. Por exemplo, podemos dizer que há um jogo de engrenagem ou um jogo de ferramentas, que outrora utilizamos em nosso cotidiano, usando-se ainda a mesma palavra para jogo de xadrez. (Brougère, 1998, p.17).

Jogo é uma situação caracterizada pelo fato de que seres se divertem, têm prazer, independentemente de sua definição. Brougère (1998) considera que o termo é compreendido e utilizado na própria ausência de definição rigorosa, isto é, jogo é o que o vocabulário científico denomina "atividade lúdica", portanto, justifica-se o uso dos vocábulos jogos, atividades lúdicas e até mesmo jogos educativos.

O jogo é também uma estrutura, um sistema de regras que existe e subsiste de modo abstrato independentemente dos jogadores, fora de sua realização concreta em um jogo. Há jogo se houver situação lúdica, presença de um sistema de regras e para nós o principal componente: o prazer (LEQUAL, 2011 ).

\section{Metodologia}

George Kelly, físico e matemático, enfocou seus estudos sob a perspectiva da psicologia humanista. Dos muitos trabalhos de sua autoria, destacamos nesse artigo a Teoria dos Construtos Pessoais. Com base neste estudo, o sétimo corolário é chamado Corolário da experiência onde “ $O$ sistema de construção de uma pessoa varia à medida que ela constrói sucessivamente, réplicas de eventos” (KELLY, 1963, p. 72). A pessoa reconstrói seus construtos para melhorar suas antecipações. Kelly amplia o que ele denominou de Ciclo da Experiência, composto por cinco etapas: antecipação, investimento, encontro, confirmação ou desconfirmação e revisão construtiva.

\section{Resultados e Discussões}

\section{UnoOxigenados}

$\checkmark$ Carta 7: Ficar em silêncio por uma rodada, quem falar, irá ser punido por cada palavra 01 carta;

$\checkmark$ Carta 0: quando a carta de número 0 (zero) for descartada, pode-se pedir para trocar de 
jogo com qualquer jogador em mesa, sendo obrigatório o indivíduo trocar as suas cartas para a pessoa que jogou a carta.

$\checkmark$ Carta Funcional (CF): É representado pelo grupo funcional

$\checkmark$ Carta das Estruturas (CE): É representado pela estrutura referente aos grupos funcionais $(\mathrm{GF})$;

$\checkmark$ Carta das Nomenclaturas (CN): É representado pela nomenclatura referente aos grupos funcionais $(\mathrm{GF})$;

$\checkmark$ Comprar Duas Cartas (CDC) +2 (Representada por duas cartas, escrito "+2" no canto superior esquerdo e no canto inferior direito da carta) . O próximo jogador compra duas cartas e perde a sua vez de jogar.

$\checkmark$ Químico Maluco (QM): +4(Representada por quatro cartas, uma amarela, uma azul, uma verde e uma vermelha, escrito " $+4 "$ no canto superior esquerdo e no canto inferior direito da carta) O jogador escolhe qual deve ser a cor para prosseguir o jogo, além de fazer o próximo jogador comprar quatro cartas e perder sua vez de jogar. Esta carta só deve ser jogada quando a pessoa não possuir outra para jogar, senão pode ser penalizada. Se essa carta iniciar o jogo, ela é devolvida ao baralho. Jogada de desafios jogando um coringa comprar quatro, e se a pessoa ao seu lado tiver um para competir o próximo e assim sucessivamente. Pode ser rebatido ao próximo jogador com um "Comprar duas" ou "Coringa Comprar quatro" (Apenas se estiver em consenso de usar a Regra Acumulativa).

$\checkmark$ Inversão: (Representada por duas setas curvadas, uma de cabeça para cima e outra de cabeça para baixo, uma em cima da outra) A ordem do jogo é invertida, do sentido horário para o sentido anti-horário e vice-versa. Se o jogo for jogado por duas pessoas, a carta é tratada com o mesmo sentido de pular.

$\checkmark$ Carta do Feiticeiro Químico (FQ): (Representada por um círculo com uma linha diagonal passando pelo centro, como se fosse um sinal de "proibido") O próximo jogador perde a sua vez de jogar.

$\checkmark$ Coringa: (Representada por uma elipse, dividida em 4 partes iguais, com cada parte de uma cor diferente (Amarelo, azul, verde e vermelho)) O jogador escolhe qual deve ser a cor para prosseguir o jogo. Esta carta pode ser jogada a qualquer momento do jogo, mesmo se o jogador tiver outra carta para usar. 


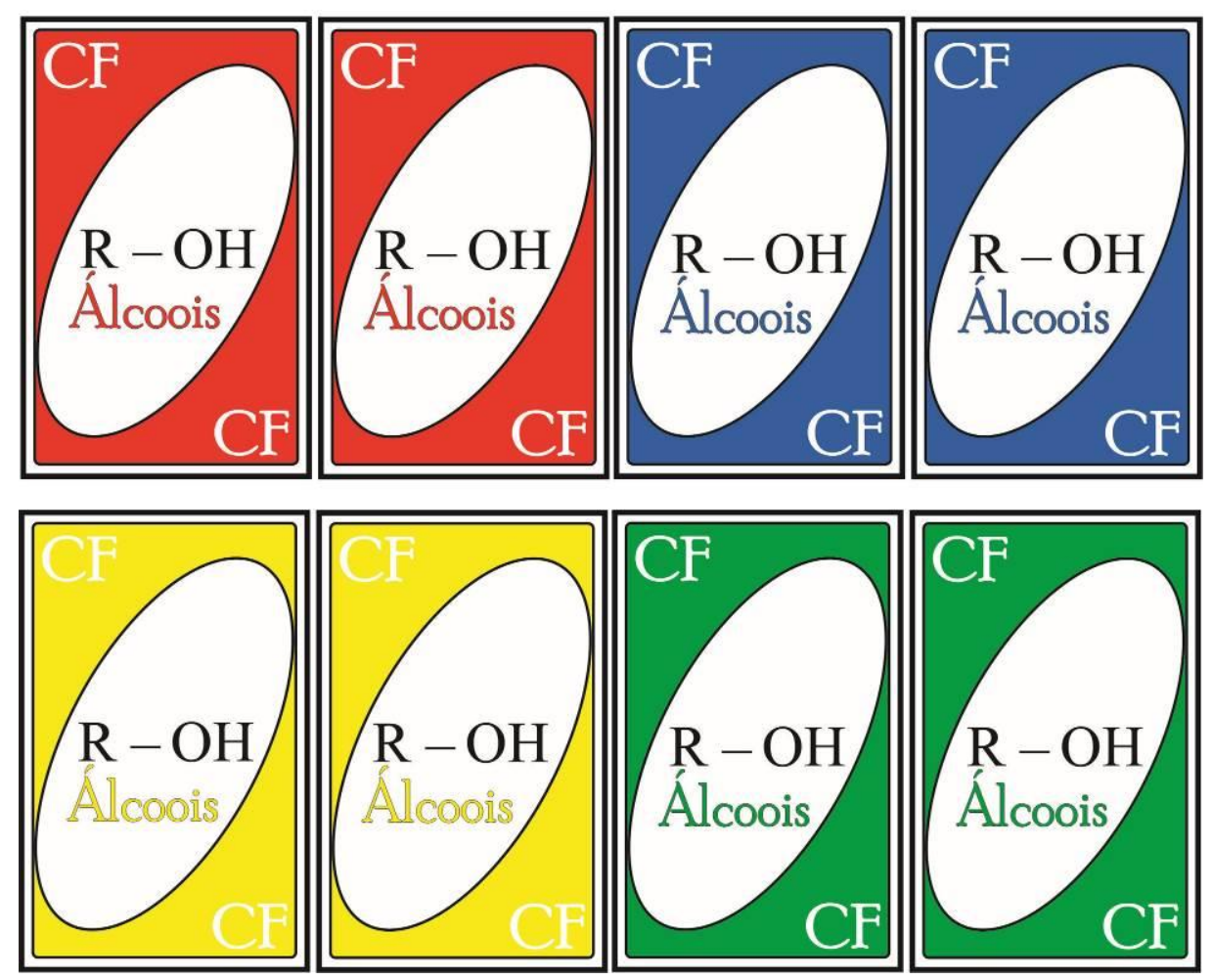

Figura 01: Carta do Grupo Funcional - Fonte: Autor (2016)
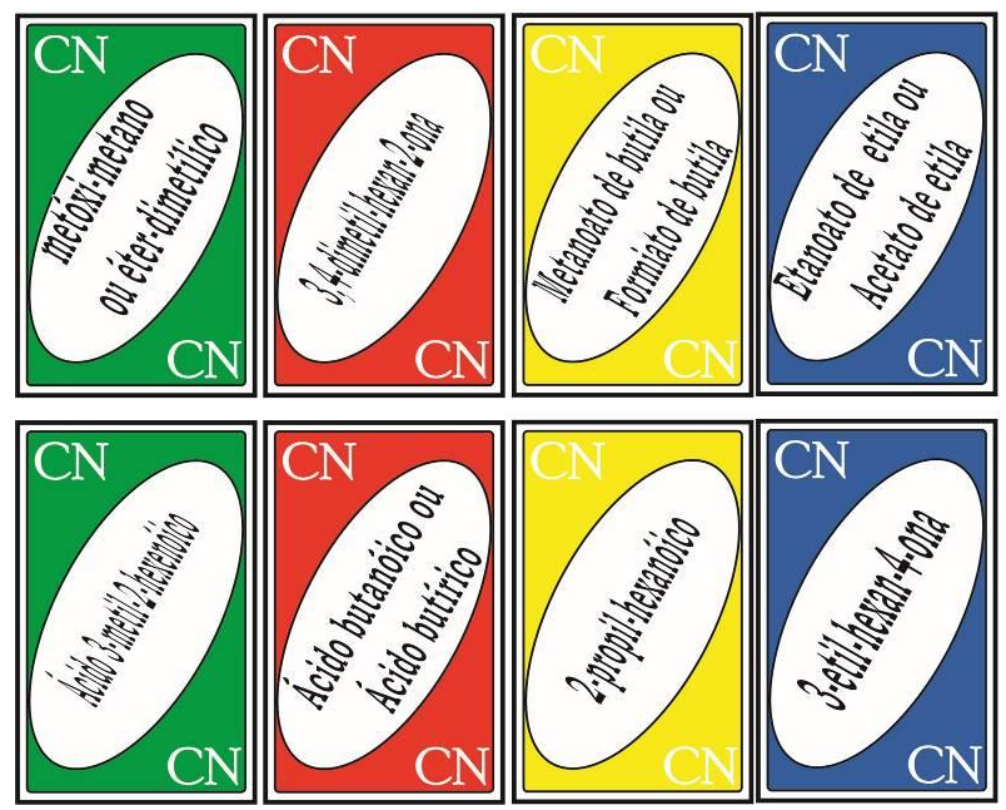

Figura 02: Carta da Nomenclatura - Fonte: Autor (2016) 


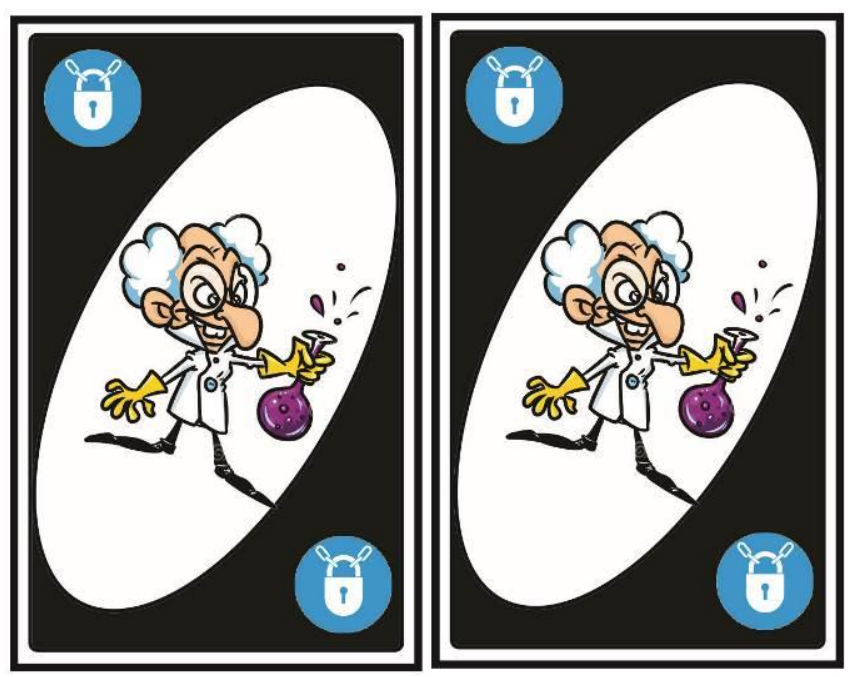

Figura 03: Carta do Feiticeiro Químico - Fonte: Autor (2016)

\section{Conclusões}

Finalmente, esperamos apresentar para a comunidade científica que o UnoOxigenado permite ao professor trabalhar com o erro dos alunos, o que geralmente não é feito nas escolas, de uma maneira prazerosa para o aluno, além de utilizarmos também como auxílio na formação de professores.

Espera-se que esse UnoOxigenado possa ajudar os estudantes dos terceiros anos do ensino médio a compreender e a diferir os grupos funcionais, nomenclaturas e estruturas das funções oxigenadas em Química Orgânica.

\section{Referências}

ARANHA, M. L. A. História da Educação. 2a ed. São Paulo: Moderna, 1996.

BROUGÈRE, G. Jogo e educação. Porto Alegre: Editora Artmed, 1998.

EVAngelista, L. M. O lúdico e a Educação Ambiental na Formação de Professores: Diálogos Possíveis. Dissertação de Mestrado, Universidade Federal de Goiás, 2009.

LEQUAL, 2011 . Laboratório de Educação Química e Atividades Lúdicas: (OLIVEIRA, 2005): Júri Químico: Uma atividade Lúdica para Ensinar Conceitos em Química; (MESQUITA, 2006): As Visões de Ciência nos Desenhos Animados Jimmy Nêutron e o Laboratório de Dexter; (CAVALCANTI, 2007): O Uso RPG (RolePlaying 165 Game) no Ensino de Química; (MENDONÇA, 2007): Jornal Científico como Atividade Lúdica para Construção de Conceitos em Química; (VAZ, 2008): O Ensino de Química para Adolescentes em Conflito com a Lei: Possibilibades e Desafios.

SOARES, M. H. F. B. O lúdico em Química: Jogos em Ensino de Química. Tese de Doutorado, UFSCar, Brasil, 2004. 